\title{
Pré-hidrólise enzimática da gordura de efluente da indústria de pescado objetivando o aumento da produção de metano
}

\author{
Enzymatic hydrolysis of fat from fish industry effluents aimed at increasing methane production
}

\author{
Angélica Moreira VALENTE ${ }^{2 *}$, Verônica Marinho ALEXANDRE ${ }^{1}$, \\ Magali Christe CAMMAROTA ${ }^{1}$, Denise Maria Guimarães FREIRE ${ }^{2}$
}

\begin{abstract}
Resumo
A aplicação de preparados enzimáticos sólidos (PES) ricos em lipases foi avaliada no tratamento anaeróbio de efluente de indústria de conservas de pescado. O PES foi produzido pelo fungo Penicillium simplicissimum por fermentação em meio sólido (FMS) de resíduo industrial, sendo empregado na hidrólise de gorduras presentes no efluente a fim de viabilizar a utilização de metano como fonte de energia. O efluente contendo $1500 \mathrm{mg} \mathrm{O \& G} \cdot \mathrm{L}^{-1}$ foi hidrolisado com $0,2,0,5$ e $1,0 \%(\mathrm{~m} / \mathrm{v})$ de PES a $30^{\circ} \mathrm{C}$ por até 18 horas. O efeito do pré-tratamento enzimático dos O\&G não foi significativo com relação à remoção de DQO, pois, independente das condições adotadas, obtiveram-se valores de 91 a $95 \%$. Por outro lado, a produção específica de metano apresentou valores que variaram com a adição do PES e o tempo de hidrólise. Em experimentos controle (sem adição de PES), a produção específica de metano aumentou com o tempo de incubação, atingindo um máximo com 18 horas (138 $\mathrm{mL} \mathrm{CH}_{4} \cdot \mathrm{g}^{-1} \mathrm{DQO}_{\text {inicial }}$ ). No entanto, valores mais elevados de produção específica de metano foram obtidos com 0,5 e 1,0\% de PES, destacando-se a hidrólise com $0,5 \%$ de PES e 8 horas de hidrólise, com $216 \mathrm{~mL} \mathrm{CH}_{4} \cdot \mathrm{g}^{-1} \mathrm{DQO}_{\text {inicial }}$. Quando se compara o experimento controle 0 horas (efluente bruto) com o efluente hidrolisado com $0,5 \%$ de PES durante 8 horas, um aumento de 2,7 vezes na produção específica de metano foi observado, indicando que a matéria orgânica foi mais facilmente assimilada pelos microrganismos anaeróbios nesta última condição.

Palavras-chave: pescado; efluentes; hidrólise; gorduras; lípases; metano.
\end{abstract}

\begin{abstract}
The application of solid lipase-rich enzymatic preparations (SEP) in the anaerobic treatment of industrial effluents from canned fish processing was investigated. SEP was produced by the fungus Penicillium simplicissimum through solid-state fermentation (SSF) of industrial wastes, and it was used in the hydrolysis of fats present in the effluents in order to facilitate the use of methane as a source of energy. The effluent (1500 mg O\&G.L $\mathrm{L}^{-1}$ ) was hydrolyzed with $0.2,0.5$ and $1.0 \%$ (w/v) of SEP at $30^{\circ} \mathrm{C}$ for up to 18 hours. The effect of the enzymatic pre-treatment of $\mathrm{O} \& \mathrm{G}$ on the COD removal was not observed because regardless of the conditions adopted, values from 91 to $95 \%$ were obtained. The specific production of methane presented values that varied with the addition of SEP and time of hydrolysis. In the control experiments, in which the flasks were incubated at $30^{\circ} \mathrm{C}$ without the addition of SEP, the specific methane production increased with the time of incubation reaching the maximum peak at $18 \mathrm{~h}\left(138 \mathrm{~mL} \mathrm{CH}_{4} \cdot \mathrm{g}^{-1} \mathrm{COD}_{\text {consumed }}\right)$. However, higher values of specific methane production were obtained with 0.5 and $1.0 \%$ of SEP highlighting the hydrolysis with $0.5 \%$ of SEP and 8 hours of hydrolysis with $216 \mathrm{~mL} \mathrm{CH}_{4} \cdot \mathrm{g}^{-1} \mathrm{COD}_{\text {comsumed }}$. When comparing the control 0 hour (raw effluent) with the effluent hydrolyzed with $0.5 \%$ of SEP for 8 hours, it could be observed that the specific methane production increased by 2.7 times indicating that the substrate available for the action of anaerobic microorganisms were more easily assimilated.

Keywords: fish; effluents; hydrolysis; fats; lypasis; methane.
\end{abstract}

\section{Introdução:}

Os efluentes gerados nas indústrias de conservas de pescado apresentam elevadas vazão e concentração de matéria orgânica biodegradável, principalmente na forma de proteínas e lipídios. $\mathrm{Na}$ caracterização desses efluentes, observa-se uma acentuada variabilidade de composição, própria do modo de operação das indústrias, tipo de pescado processado e época do ano, entre outros fatores (LUCAS; KOETZ; PRZYBYLSK, 2000). Em um levantamento feito por Rollón (1999), efluentes de indústrias processadoras de atum e sardinha apresentam as seguintes faixas de variação: $\mathrm{pH}(5,6-7,2), \mathrm{DBO}-$ Demanda Bioquímica de Oxigênio (710-14500 mg.L $\left.\mathrm{L}^{-1}\right)$, DQO - Demanda Química de Oxigênio total (1500-53600 mg.L-1), DQO solúvel
(1250-52100 mg.L $\mathrm{L}^{-1}$ ), sólidos totais (550-12400 mg.L-1 ) e NKT nitrogênio Kjeldahl total (82-703 mg. $\left.\mathrm{L}^{-1}\right)$.

Diferentes efluentes são gerados ao longo das várias etapas de processamento do pescado, tais como recepção do pescado, condensação nas câmaras frigoríficas, evisceração, salmoura, acondicionamento em latas, cozimento, adição de óleo, recravação e lavagem das latas, autoclavagem e lavagens para resfriamento. Além das águas de lavagens do pescado, têm-se também as lavagens de pisos e equipamentos, e ainda são incluídos nesses efluentes os esgotos sanitários dos funcionários. Tais operações geram grandes volumes de resíduos sólidos

Recebido para publicação em 10/7/2008

Aceito para publicação em 5/1/2009 (003662)

1 Departamento de Engenharia Bioquímica, Universidade Federal do Rio de Janeiro - UFRJ, Rio de Janeiro - RJ, Brasil

${ }^{2}$ Ciência de Alimentos, Universidade Federal do Rio de Janeiro - UFRJ, Rio de Janeiro - RJ, Brasil, E-mail: valenteam@terra.com.br

* A quem a correspondência deve ser enviada 
e líquidos. A maior parte dos resíduos sólidos é facilmente removida no próprio sistema produtivo ou no gradeamento e peneiramento das águas residuárias. Desta forma, o potencial poluidor, no tocante à disposição, se restringe aos resíduos líquidos. Em muitas indústrias, esses efluentes são lançados nos cursos d'água adjacentes sem um tratamento adequado, contribuindo para a poluição do meio ambiente e produzindo impactos na biota e na qualidade das águas (SILVA; BATISTA, 2003).

Atualmente, existe uma variedade de tecnologias que se aplicam ao tratamento desses efluentes. Os tratamentos físicoquímicos, com adição de coagulantes químicos (como sulfato de alumínio e cloreto férrico), permitem uma remoção parcial da matéria orgânica devido à precipitação de proteínas e gorduras. No entanto, o custo com produtos químicos é elevado, a gordura dissolvida ou emulsionada não é removida de forma eficiente e lodos, extremamente problemáticos para tratamento e descarte, são produzidos (LUCAS; KOETZ; PRZYBYLSK, 2000). Os processos biológicos são empregados em grande parte dos casos, destacando-se os processos biológicos anaeróbios, que vêm sendo largamente utilizados no tratamento de efluentes da indústria de pescado em função de sua elevada carga orgânica biodegradável (ROLLÓN, 1999).

Nos biorreatores anaeróbios, entretanto, os lipídios causam problemas, como o desenvolvimento de lodos com baixa atividade, com inadequadas características físicas e com elevada tendência de flotação; produção de escuma; colmatação do leito de lodo; e arraste da biomassa, levando à perda de eficiência e até mesmo ao colapso do reator. Além disso, a adsorção de gorduras à superfície do lodo dificulta o transporte de substratos solúveis para a biomassa, levando à queda da taxa de conversão desses substratos (PEREIRA, 2004; JEGANATHAN; NAKHLA; BASSI, 2007)

Processos alternativos têm sido utilizados na redução da concentração de lipídios contidos nos efluentes por meio da ação de enzimas lipolíticas. Essas enzimas apresentam uma importância particular pelo fato de hidrolisarem especificamente óleos e gorduras, o que pode ser de grande interesse para o tratamento de efluentes com alto teor desses materiais. As lipases (glicerol éster hidrolases, E.C.3.1.1.3) compreendem um grupo de enzimas hidrolíticas que atuam na interface orgânico-aquosa, catalisando a hidrólise de ligações éster-carboxílicas presentes em acilgliceróis. A sua utilização reduz os níveis de sólidos suspensos e lipídios, o que possibilita melhores condições de operação no tratamento anaeróbio, além de remover filmes oleosos em tubulações, resultando no aumento da vida útil dos equipamentos (MENDES, 2004).

A aplicação de uma tecnologia híbrida (tratamento enzimático associado ao tratamento biológico) constitui importante recurso para o tratamento de efluentes com elevado teor de gordura. A etapa de pré-tratamento enzimático elimina ou reduz significativamente o teor de triglicerídeos no efluente, permitindo uma melhor atuação da população microbiana em uma etapa posterior de tratamento biológico. Ainda assim, o custo das enzimas utilizadas no pré-tratamento deve ser reduzido, a fim de viabilizar sua aplicação em escala industrial. Portanto, é importante que se busquem soluções tecnológicas simples e de baixo custo para atender a esta demanda, como, por exemplo, a produção de enzimas através do processo de fermentação em meio sólido (FMS), que utiliza rejeitos agroindustriais como meio de cultivo (CAMMAROTA; FREIRE, 2006).

A utilização de enzimas no tratamento de efluentes como alternativa ou complemento aos tratamentos convencionais já vem sendo realizada com muito sucesso, em escala laboratorial, pelo Núcleo de Biotecnologia da UFRJ (CAMMAROTA; TEIXEIRA; FREIRE, 2001; LEAL et al., 2002; ROSA; FREIRE; CAMMAROTA, 2006; VALLADÃO; FREIRE; CAMMAROTA, 2007). O emprego destes preparados enzimáticos no tratamento de efluentes da indústria de pescado também deve ser avaliado para reduzir os problemas mencionados no tratamento de efluentes com alto teor de gordura e proteínas, além de possibilitar a conversão do carbono orgânico na forma de gorduras e proteínas, antes descartadas como resíduos sólidos problemáticos, em metano, que pode ser aproveitado como fonte de energia na própria indústria.

O principal objetivo deste estudo foi avaliar a eficiência de um preparado enzimático sólido (PES) rico em lipases, produzido pelo fungo Penicillium simplicissimum por fermentação em meio sólido, na hidrólise das gorduras, a fim de viabilizar a geração e aproveitamento do metano como fonte de energia em uma indústria de pescado.

\section{Material e métodos}

\subsection{Fermentação em Meio Sólido (FMS)}

Para a produção do preparado enzimático sólido (PES), foi utilizada uma cultura pura do fungo Penicillium simplicissimum, oriunda da Coleção de Culturas do Laboratório de Biotecnologia Microbiana (LaBiM - UFRJ). Esta cepa foi isolada por Freire (1996) de um resíduo agroindustrial proveniente da expressão da amêndoa de babaçu. Este resíduo, denominado torta de babaçu, foi utilizado como meio de cultivo basal para a fermentação, que foi conduzida por 72 horas com a torta de babaçu moída e peneirada (diâmetro médio de $0,315 \mathrm{~mm}$ ). O teor de umidade foi mantido em $70 \%$ e a temperatura em $30{ }^{\circ} \mathrm{C}$ (GUTARRA et al., $2005,2007)$. Após a fermentação, parte da torta fermentada foi extraída e utilizada para determinação da atividade lipásica, segundo metodologia descrita em Gutarra et al., (2007). O restante da torta fermentada foi embalado a vácuo, estocado em freezer a $-20{ }^{\circ} \mathrm{C}$ e utilizado posteriormente na etapa de hidrólise enzimática do efluente, sendo denominado preparado enzimático sólido (PES). A atividade enzimática média obtida para o PES foi de $134 \pm 7{\mathrm{U} . g^{-1}}^{\text {de torta seca. }}$

\subsection{Caracterização do efluente, gordura e lodo}

O efluente empregado neste estudo foi coletado em uma indústria de conservas de pescado após as etapas de flotação (para remoção de gordura) e equalização, sendo mantido a $-8^{\circ} \mathrm{C}$ até seu uso. $\mathrm{O}$ efluente apresentou as seguintes características: $\mathrm{pH}=6,7, \mathrm{DQO}=3725 \mathrm{mg} \cdot \mathrm{L}^{-1}, \mathrm{DBO}_{5}=2860 \mathrm{mg} \cdot \mathrm{L}^{-1}$, $\mathrm{O} \& \mathrm{G}=711 \mathrm{mg} \cdot \mathrm{L}^{-1}$, Nitrogênio Kjeldahl Total $=1362 \mathrm{mg} \cdot \mathrm{L}^{-1} \mathrm{e}$ Fósforo Total $=5,3 \mathrm{mg} . \mathrm{L}^{-1}$. 
Já a gordura coletada na superfície do flotador (flotado) apresentou $39,7 \%$ de umidade e $63,6 \%$ de O\&G (em base seca). O teor de O\&G a ser avaliado nas etapas de hidrólise e biodegradabilidade anaeróbia foi obtido através da adição de quantidades apropriadas desta gordura ao efluente coletado após o flotador. Como na indústria de pescado fornecedora do efluente os maiores teores de O\&G alcançados situavam-se em torno de $1500 \mathrm{mg} . \mathrm{L}^{-1}$, este valor foi selecionado para os estudos iniciais de hidrólise enzimática e biodegradabilidade anaeróbia relatados neste trabalho.

O lodo empregado nos testes de biodegradabilidade anaeróbia foi proveniente de um reator do tipo UASB (upflow anaerobic sludge blanket) em operação na mesma indústria de pescado. Este apresentava um teor de SVS de 51780 mg.L $\mathrm{L}^{-1}$.

\subsection{Hidrólise enzimática do efluente}

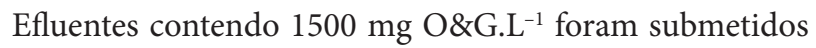
a hidrólises com diferentes concentrações de PES (0,2, 0,5 e $1,0 \%(\mathrm{~m} / \mathrm{v}))$. As concentrações de PES eram semelhantes às empregadas em trabalhos com efluentes de laticínios e de abatedouro de aves (CAMMAROTA; TEIXEIRA; FREIRE, 2001, 2001; ROSA; FREIRE; CAMMAROTA, 2006; VALLADÃO; FREIRE; CAMMAROTA, 2007).

A hidrólise foi realizada a $30{ }^{\circ} \mathrm{C}$ em reatores de vidro contendo $2000 \mathrm{~mL}$ de efluente com agitação de $150 \mathrm{rpm}$, em equipamento Jar-Test, durante 20 horas. O monitoramento da cinética da hidrólise foi realizado pela titulação dos ácidos livres liberados. Para tal, alíquotas de efluente foram coletadas a cada 2 horas, até 20 horas de hidrólise. Após a coleta de cada alíquota $(10 \mathrm{~mL})$, a reação de hidrólise era imediatamente interrompida pela adição de $10 \mathrm{~mL}$ de uma solução acetona: etanol (1:1), sendo o teor de ácidos livres determinado em titulador automático.

\subsection{Ensaios de biodegradabilidade anaeróbia}

Ensaios de biodegradabilidade anaeróbia foram realizados com os efluentes brutos (sem adição de PES) e com os efluentes pré-tratados enzimaticamente (com adição de PES) no início (0 horas) e após 4,8 e 18 horas de incubação a $30^{\circ} \mathrm{C}$. Os testes foram conduzidos em batelada, em frascos tipo penicilina de $100 \mathrm{~mL}$, com $90 \mathrm{~mL}$ de volume útil, composto de lodo anaeróbio e efluente bruto ou pré-tratado. A quantidade de lodo utilizada em cada ensaio foi calculada para se manter uma relação DQO (inicial do efluente): SVS - sólidos voláteis suspensos (lodo) de 1:1. O pH dos efluentes foi ajustado para 7,0 $\pm 0,2$ antes da mistura com o lodo. Os frascos foram incubados a $30^{\circ} \mathrm{C}$ por até 19 dias. A biodegradabilidade foi avaliada através da medida de eficiência de remoção de DQO e produção de biogás. A média do volume de biogás foi realizada por deslocamento do êmbolo de seringas plásticas graduadas de $20 \mathrm{~mL}$ conectadas aos frascos. Alíquotas para determinação da DQO (denominadas DQO inicial) foram tomadas após a hidrólise, sem a mistura com o lodo anaeróbio. A DQO final foi determinada no último dia do ensaio de biodegradabilidade (19 dias), após abertura dos frascos.

\subsection{Métodos analíticos}

A atividade lipásica do extrato bruto foi determinada por método espectrofotométrico, utilizando-se p-nitrofenillaureato como substrato, conforme descrito por Gutarra et al. (2005). Uma unidade de atividade lipásica é definida como a quantidade de enzima que libera $1 \mu \mathrm{mol}$ de p-nitrofenol por minuto, nas condições de reação. O teor de ácidos livres na etapa de pré-hidrólise enzimática foi determinado por titulação em titulador automático (end-point $\mathrm{pH} 11$ ), utilizando-se $\mathrm{NaOH}$ 0,04 mol.L-1 como titulante. Análises de DQO e outros parâmetros empregados na caracterização do efluente e da gordura foram conduzidos de acordo com American Public Health Association (1992). O teor de metano no biogás foi analisado por cromatografia gasosa em cromatógrafo SHIMADZU GC-17A, empregando-se coluna CHROMPACK Sílica Plot $-50 \mathrm{~m} \times 0,32 \mathrm{~mm}$, hidrogênio como gás de arraste $(5,0 \mathrm{~mL} /$ minutos $)$, temperaturas do injetor, coluna e detector de ionização de chama de 160,30 e $250{ }^{\circ} \mathrm{C}$, respectivamente, tempo de análise de 4 minutos e split de 1:20.

\section{Resultados e discussão}

Na Tabela 1 é apresentada a produção de ácidos livres durante a hidrólise das gorduras presentes no efluente contendo $1500 \mathrm{mg}$ O\&G.L $\mathrm{L}^{-1}$ com diferentes teores de PES $(0,2,0,5 \mathrm{e}$ $1,0 \% \mathrm{~m} / \mathrm{v}$ ). Como se pode observar, a diferença entre os ácidos livres produzidos no experimento controle (sem adição de PES) e nos experimentos com efluente contendo a enzima não foi marcante, apesar de ter aumentado com o teor de PES na hidrólise. A produção de ácidos livres no experimento controle e com o efluente após hidrólise com 1,0\% de PES foi de 10,0 e $11,0 \mu \mathrm{mol} . \mathrm{mL}^{-1}$, respectivamente.

Os baixos valores de produção de ácidos livres no meio reacional se devem ao fato de haver produção e consumo simultâneos. Os microrganismos, presentes no próprio efluente e na gordura adicionada para compor o teor inicial desejado de O\&G, utilizam os ácidos graxos liberados na hidrólise como substrato, reduzindo sua concentração no meio (LEAL et al., 2002). Por este motivo, não se pode avaliar a eficiência do prétratamento enzimático apenas pelo perfil de hidrólise, tornandose necessários os testes de biodegradabilidade. Embora não tenha sido detectada diferença expressiva na produção de ácidos livres, a composição do efluente pode ter sido modificada com a adição do PES, alterando consideravelmente a biodegradabilidade anaeróbia do efluente de pescado.

Tabela 1. Concentração de ácidos livres liberados durante a hidrólise

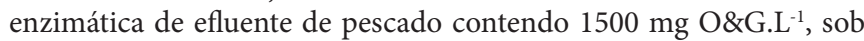
diferentes teores de PES com atividade lipásica média de 134 U.G ${ }^{-1}$, a $30{ }^{\circ} \mathrm{C}$.

\begin{tabular}{ccccc}
\hline \multirow{2}{*}{$\begin{array}{c}\text { Tempo de hidrólise } \\
\text { (horas) }\end{array}$} & \multicolumn{4}{c}{ Ácidos livres $\left(\mu \mathrm{mol} . \mathrm{mL}^{-1}\right)$} \\
\cline { 2 - 5 } & Controle & $0,2 \%$ PES & $0,5 \%$ PES & $1,0 \%$ PES \\
\hline 0 & 18,5 & 19,2 & 19,3 & 19,5 \\
4 & 19,4 & 19,7 & 20,1 & 20,9 \\
8 & 22,0 & 23,1 & 24,0 & 24,4 \\
18 & 28,1 & 29,2 & 29,7 & 30,0 \\
20 & 28,5 & 29,1 & 29,9 & 30,5 \\
$\Delta \mathrm{T}$ & 10,0 & 9,9 & 10,6 & 11,0 \\
\hline $\mathrm{T}=\mathrm{T}_{20}-\mathrm{T}_{0}=$ Produção de ácidos livres após 20 horas de hidrólise.
\end{tabular}


Os testes de biodegradabilidade foram realizados com amostras de efluente coletadas nos experimentos controle e com adição de PES em diferentes tempos de hidrólise (4, 8 e 18 horas).

A Figura 1 representa a produção de biogás ao longo do período de incubação, em cada uma das condições avaliadas.
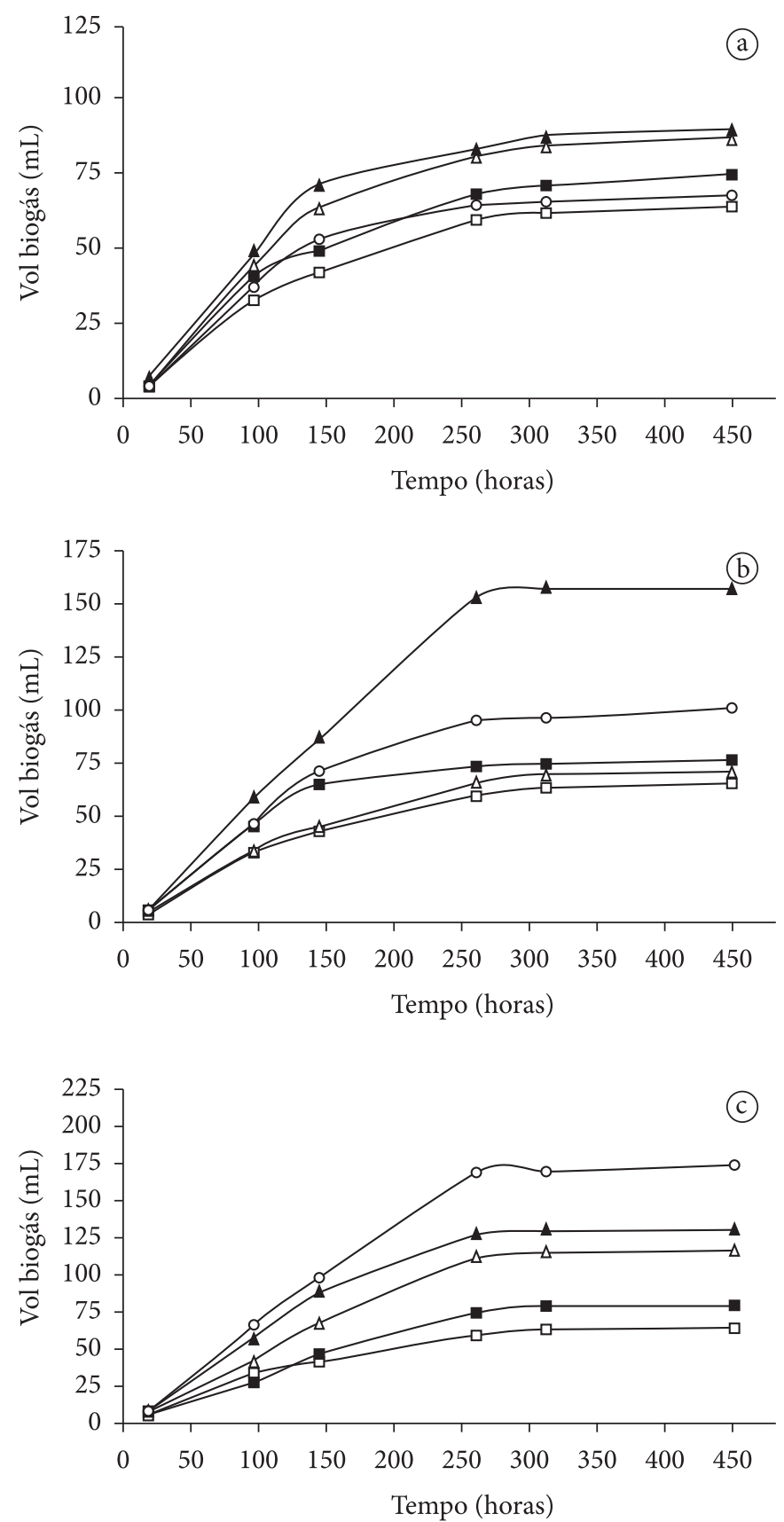

$\rightarrow$ CT 0 horas $\rightarrow$ CT 4 horas $\rightarrow-$ PS $0,2 \% 4$ horas

$₫$ PS $0,5 \% 4$ horas -o- PS $1,0 \% 4$ horas

Figura 1. Evolução da produção de biogás no primeiro contato do lodo com o efluente sem adição de PES no início (CT 0 horas) e após 18 horas a $30^{\circ} \mathrm{C}$ (CT 18 horas), e com os efluentes hidrolisados com $0,2,0,5$ ou $1,0 \%(\mathrm{~m} / \mathrm{v})$ de PES a $30^{\circ} \mathrm{C}$ por 4 horas (A), 8 horas (B) e 18 horas $(\mathrm{C})$.
As curvas de produção de biogás mostram que a permanência do efluente sob agitação a $30^{\circ} \mathrm{C}$, mesmo sem adição de enzima (experimentos controle 4,8 e 18 horas), modifica sua composição, pois a produção de biogás é levemente maior ao final destes experimentos (73 a $80 \mathrm{~mL}$ ), quando comparada ao controle 0 horas $(65 \mathrm{~mL})$.

No entanto, nos experimentos com efluente previamente hidrolisado, os volumes finais, assim como as velocidades máximas de produção de biogás, atingem valores significativamente maiores, comparados aos respectivos controles. Ademais, a combinação entre concentração de PES e tempo de hidrólise gerou diferentes resultados em termos de velocidade máxima de produção e volume final de biogás. Por exemplo, nos experimentos com amostras submetidas a 4 horas de hidrólise (Figura 1A), o volume final e a velocidade máxima de produção de biogás aumentam com 0,2\% (87 e 0,49 $\mathrm{mL} \mathrm{CH}_{4} /$ horas) e 0,5\% (90 e $0,52 \mathrm{~mL} \mathrm{CH}_{4}$ /horas) de PES. Com 1,0\% de PES, o volume final de biogás é menor (68 e $0,38 \mathrm{~mL} \mathrm{CH}_{4} /$ horas), mas com velocidade máxima de produção similar a do controle $(73 \mathrm{e}$ $0,37 \mathrm{~mL} \mathrm{CH}_{4} /$ horas).

Com 8 horas de hidrólise (Figura 1B), a adição de 0,2\% de PES gera resultados inferiores aos obtidos no controle (71 e $0,35 \mathrm{~mL} \mathrm{CH}_{4} /$ horas e 76 e $0,46 \mathrm{~mL} \mathrm{CH}_{4}$ /horas, respectivamente), ao contrário da adição de $0,5 \%$ de PES, que apresenta uma produção de biogás ( 155 e $0,61 \mathrm{~mL} \mathrm{CH}_{4} /$ horas) muito maior que a de todos os demais experimentos. Neste tempo de hidrólise, o teor de 1,0\% de PES também parece apresentar efeito inibitório sobre o consórcio anaeróbio, pois, em comparação com $0,5 \%$ de PES, ocorre uma redução acentuada do volume final e da velocidade de produção do biogás (100 e $0,52 \mathrm{~mL} \mathrm{CH}_{4}$ /horas).

O efluente adicionado de $1,0 \%$ de PES e submetido à hidrólise, provavelmente, contém ácidos graxos de cadeia longa (VALLADÃO; FREIRE; CAMMAROTA, 2007). Estas substâncias inibem os microrganismos anaeróbios e a biodegradabilidade da amostra se torna menor. Com 18 horas de hidrólise, já não se observa mais essa inibição, pois este tempo pode ser suficiente para que essas substâncias sejam degradadas a moléculas menores, menos inibitórias e mais biodegradáveis. Além disso, percebe-se claramente que o volume final de biogás aumenta com o teor de enzima, obtendo-se $80 \pm 8,116 \pm 1$, $131 \pm 5$ e $175 \pm 7 \mathrm{~mL}$ de biogás para o controle, 0,2, 0,5 e 1,0\% de PES, respectivamente, ao final dos experimentos (Figura 1C). O mesmo se observa para a velocidade máxima de produção de biogás, que apresenta valores de $0,20,0,43,0,49$ e $0,67 \mathrm{~mL}$ $\mathrm{CH}_{4} /$ horas nos experimentos controle, $0,2,0,5$ e 1,0\% de PES, respectivamente.

A remoção da DQO também foi avaliada nos experimentos de biodegradabilidade anaeróbia, sendo os resultados obtidos apresentados na Tabela 2, juntamente com os dados relativos à produção de metano. Pode-se observar que os percentuais de metano (57 a 69\%), assim como a remoção de DQO (91 a 95\%), apresentaram pouca variação em todas as condições estudadas. Tal fato não indica que percentuais semelhantes de matéria orgânica tenham sido assimilados pelos microrganismos, pois uma parte considerável da DQO pode ter sido removida por 
Tabela 2. Resultados dos testes de biodegradabilidade anaeróbia.

\begin{tabular}{|c|c|c|c|c|c|c|c|}
\hline Condição & $\begin{array}{l}\text { DQO inicial } \\
\left(\mathrm{mg} \cdot \mathrm{L}^{-1}\right)\end{array}$ & $\begin{array}{l}\text { DQO final } \\
\left(\mathrm{mg} \cdot \mathrm{L}^{-1}\right)\end{array}$ & $\begin{array}{c}\text { Remoção DQO } \\
\text { (\%) }\end{array}$ & $\begin{array}{l}\text { Volume biogás } \\
(\mathrm{mL})^{*}\end{array}$ & $\% \mathrm{CH}_{4}$ & $\begin{array}{l}\text { Volume } \mathrm{CH}_{4} \\
\quad(\mathrm{~mL})\end{array}$ & $\begin{array}{c}\text { PEM } \\
\left(\mathrm{mL} \mathrm{CH}_{4} \cdot \mathrm{g}^{-1} \mathrm{DQO}\right)\end{array}$ \\
\hline Controle 0 horas & 5700 & 375 & 93 & 65 & 62 & 40 & 79 \\
\hline Controle 4 horas & 4950 & 365 & 93 & 73 & 63 & 46 & 103 \\
\hline $0,2 \% 4$ horas & 5450 & 397 & 93 & 87 & 65 & 57 & 115 \\
\hline $0,5 \% 4$ horas & 6700 & 411 & 94 & 90 & 65 & 57 & 115 \\
\hline $1,0 \% 4$ horas & 8600 & 395 & 95 & 68 & 61 & 41 & 54 \\
\hline $0,5 \% 8$ horas & 5500 & 406 & 93 & 155 & 69 & 107 & 216 \\
\hline $1,0 \% 8$ horas & 6100 & 493 & 92 & 100 & 65 & 65 & 118 \\
\hline Controle 18 horas & 4175 & 392 & 91 & 80 & 65 & 52 & 138 \\
\hline $0,2 \% 18$ horas & 4600 & 374 & 92 & 116 & 65 & 75 & 182 \\
\hline 0,518 horas & 5400 & 384 & 93 & 132 & 61 & 81 & 166 \\
\hline
\end{tabular}

${ }^{*}$ Determinado a $30^{\circ} \mathrm{C}$ e 1 atm; e $\mathrm{PEM}=$ produção específica de metano.

adsorção ao lodo. Rollón (1999) empregou um reator UASB na avaliação do tratamento de efluentes da indústria de pescado (atum e sardinha), observando uma eficiência de remoção de DQO de $78 \pm 8 \%$.

Considerando-se que a adição de diferentes concentrações de PES e tempos de hidrólise resultaram em alterações de composição dos efluentes no início dos testes de biodegradabilidade (diferentes valores de DQO inicial), uma forma mais correta de se avaliar os efeitos destas diferentes condições de pré-hidrólise é através da determinação da produção específica de metano, ou seja, do volume de metano produzido em relação à DQO inicial introduzida no sistema. De acordo com os dados apresentados na Tabela 2 , verifica-se que a produção específica de metano, à exceção do experimento com efluente hidrolisado com 1,0\% de PES por 4 horas, foi maior em todos os experimentos com efluente previamente hidrolisado em comparação aos experimentos conduzidos com efluente bruto. A condição que mais se aproximou do valor teórico máximo esperado, considerando-se o aproveitamento de toda a matéria orgânica introduzida $\left(388,5 \mathrm{~mL} \mathrm{CH}_{4} \cdot \mathrm{g}^{-1} \mathrm{DQO}\right.$ a $\left.30^{\circ} \mathrm{C}, 1 \mathrm{~atm}\right)$, foi a hidrólise com $0,5 \%$ de PES por 8 horas, que apresentou uma produção específica de $216 \mathrm{~mL} \mathrm{CH}_{4} \cdot \mathrm{g}^{-1}$ DQO (56\% do máximo esperado).

Apesar da etapa de pré-hidrólise ter aumentado consideravelmente a produção de metano, os baixos valores obtidos para sua produção específica indicam que o processo de biodegradação anaeróbia ainda pode ser melhorado, através de adaptações sucessivas dos microrganismos do consórcio empregado como inóculo aos constituintes do PES e produtos da hidrólise.

Análises de O\&G de todo o conteúdo dos frascos de penicilina ao fim do experimento com $0,5 \%$ de PES por 8 horas revelaram uma concentração de 22,0 $\pm 1,4 \mathrm{mg} . \mathrm{L}^{-1}$. Como a hidrólise foi feita com um teor de O\&G inicial de $1500 \mathrm{mg} . \mathrm{L}^{-1}$, o tratamento (hidrólise e tratamento anaeróbio) resultou em uma remoção de $98 \%$ de O\&G. Pode-se concluir que a melhor condição de pré-tratamento foi a hidrólise com 0,5\% de PES durante 8 horas pois, além de apresentar uma produção específica de metano muito superior a de qualquer outra condição, também gerou um menor acúmulo de O\&G na biomassa do tratamento anaeróbio.

A presença de matéria orgânica prontamente metabolizável, proporcionada pela etapa de pré-hidrólise, diminui o acúmulo de gordura nos flocos de lodo, visto que a etapa limitante da degradação dos lipídios pelos microrganismos é a sua hidrólise (MENDES; PEREIRA; CASTRO, 2006). Os resultados reportados no presente trabalho são bastante interessantes, visto que o acúmulo de gordura na biomassa dos reatores, além de representar uma perda industrial importante, interfere negativamente nos sistemas de tratamento de efluentes, causando problemas como produção de escuma, colmatação do leito de lodo e arraste da biomassa, levando à perda de eficiência e até mesmo ao colapso do reator (PETRUY; LETTINGA, 1997).

\section{Conclusões}

A aplicação do preparado enzimático sólido, produzido pelo fungo Penicillium simplicissimum por fermentação em meio sólido numa etapa de hidrólise enzimática, anterior ao tratamento biológico, se mostrou uma boa opção de tratamento de efluentes gerados em indústrias de pescado. A pré-hidrólise,

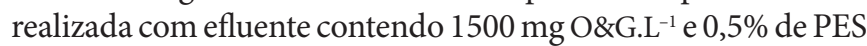
durante oito horas, resultou em maior produção de metano no tratamento anaeróbio posterior.

Esta nova forma de condução do processo de hidrólise de efluentes com elevados teores de gordura faz com que este tipo de tratamento (enzimático/biológico) seja uma alternativa interessante em escala industrial pelas seguintes razões: o pool enzimático é obtido a um custo baixo, pois é produzido por fermentação em meio sólido a partir de resíduos agroindustriais; insere-se a possibilidade de utilização de toda a carga orgânica do efluente para a produção de metano; e a redução ou mesmo eliminação de problemas operacionais decorrentes 
da presença de gordura no efluente pode ser uma realidade, especialmente, em biorreatores anaeróbios.

\section{Referências bibliográficas}

AMERICAN PUBLIC HEALTH ASSOCIATION - APHA. Standard methods for the examination of water and wastewater. $18 \mathrm{ed}$. New York, 1992.

CAMMAROTA, M. C.; TEIXEIRA, G. A.; FREIRE, D. M. G. Enzymatic pre-hydrolysis and anaerobic degradation of wastewaters with high fat contents. Biotechnology Letters, v. 23, n. 19, p. 1591-1595, 2001.

CAMMAROTA, M. C.; FREIRE, D. M. A review on hidrolytic enzymes in the treatment of wastewaters with high oil and grease content. Bioresource Biotechnology, v. 97, n. 17, p. 2195-2210, 2006.

FREIRE, D. M. G. Seleção de microrganismos lipolíticos e produção de lipase por Penicillium restrictum. Tese (Doutorado em Bioquímica) - Universidade Federal do Rio de Janeiro, Rio de Janeiro, 1996.

GUTARRA, M. L. E. et al. Lipase production by solid-state fermentation: cultivation conditions and operation of tray and packed-bed bioreactors. Applied Biochemical Biotechnology, v. 121, n. 3, p. 105-116, 2005.

GUTARRA, M. L. E. et al. Inoculum strategies for Penicillium simplicissimum lipase production by solid state fermentation using a residue of the babassu oil industry. Journal of Chemical Technology Biotechnology, v. 82, n. 9, p. 313-318, 2007.

JEGANATHAN, J.; NAKHLA, G.; BASSI, A. Oily wastewater treatment using a novel hybrid PBR-UASB system, Chemosphere, v. 67, n. 8, p. 1492-1501, 2007.

LEAL, M. C. M. R. et al. Hydrolytic enzymes as coadjuvants in the anaerobic treatment of dairy wastewaters. Brazilian Journal Chemical Engineering, v. 19, n. 2, p. 175-180, 2002.
LUCAS, A. P. C.; KOETZ, P. R.; PRZYBYLSKI, S. L. A. Tratamento anaeróbio de efluentes do processamento de corvina (Micropogonias furnieri) em reator UASB. Vetor, v. 10, n. 9, p. 113-124, 2000.

MENDES, A. A. Avaliação da biodegradabilidade de efluentes com alto teor de lipídeos previamente tratados com enzimas hidrolíticas. 2004. 135 p. Dissertação (Mestrado em Engenharia Química) - Faculdade de Engenharia Química de Lorena, Lorena, 2004.

MENDES, A. A.; PEREIRA, E. B.; CASTRO, H. F. Effect of enzymatic hydrolysis pretreatment of lipids-rich wastewater on anaerobic biodigestion. Biochemical Engineering Journal, v. 32, n. 3, p. 185-190, 2006.

PEREIRA, E. B. Tratamento enzimático para remoção de gorduras dos resíduos gerados por indústrias de produtos avícolas. 2004. $154 \mathrm{f}$. Tese (Doutorado em Engenharia Química) - Universidade Federal de Santa Catarina, Florianópolis, 2004.

PETRUY, R.; LETTINGA, G. Digestion of milk-fat emulsion. Bioresource Technology, v. 61, n.2, p. 141-149, 1997.

ROLLÓN, A. P. Anaerobic digestion of fish processing wastewater with special emphasis on hydrolysis of suspended solids. 1999. $123 \mathrm{f}$. Tese (Doutorado) - Wageningen Agricultural University, Wageningen, 1999.

ROSA, D. R.; FREIRE, D. M. G.; CAMMAROTA, M. C. Production and utilization of a new solid enzymatic preparation produced by Penicillium restrictum in activated sludge systems treating wastewater with high levels of oil and grease, Enviromental Engineering Science, v. 23, n.7, p. 813-822, 2006.

SILVA, R. G.; BATISTA, M. A. Processos industriais e sistemas de tratamento de efluentes na indústria de conserva de pescado: estudo de caso Coqueiro indústria de pescado. 2003. $65 \mathrm{f}$. Monografia (Especialização em Engenharia Sanitária e Ambiental) Universidade Estadual do Rio de Janeiro, Rio de Janeiro, 2003.

VALLADÃO, A. B. G.; FREIRE, D. M. G.; CAMMAROTA, M. C. Enzymatic pre-hydrolysis applied to the anaerobic treatment of effluents from poultry slaughterhouses, International Biodeterioration \& Biodegradation, v. 60, n.4, p. 219-225, 2007. 